\title{
Anisotropia e confinamento hidráulico do Sistema Aquífero Guarani em Ribeirão Preto (SP, Brasil)
}

Anisotropy and hydraulic confinement of the Guarany Aquifer system in Ribeirão Preto (SP, Brazil)

\author{
Ingo Wahnfried ${ }^{1}$, Amélia João Fernandes², Ricardo Hirata ${ }^{3}$, Carlos Henrique Maldaner ${ }^{4}$, Cláudia Luciana Varnier², \\ Luciana Martins Rodrigues Ferreira ${ }^{2}$, Mara Akie Iritani ${ }^{2}$, Márcia Maria Nogueira Pressinotti ${ }^{2}$ \\ ${ }^{1}$ Departamento de Geociências, Universidade Federal do Amazonas - UFAM, Avenida General Rodrigo Octávio, 6.200, \\ CEP 69080-900, Manaus, AM, BR (iwahnfried@ufam.edu.br) \\ 2Instituto Geológico, Secretaria do Meio Ambiente do Estado de São Paulo, São Paulo, SP, BR (amelia@sp.gov.br; \\ claudia.varnier@sp.gov.br; Imrferreira@sp.gov.br; mara.iritani@sp.gov.br; marciapressinotti@hotmail.com) \\ ${ }^{3}$ Centro de Pesquisas de Águas Subterrâneas, Universidade de São Paulo - CEPAS/USP, São Paulo, SP, BR (rhirata@usp.br) \\ ${ }^{4}$ G360 Institute for Groundwater Research, University of Guelph, Ontário, Canadá (cmaldane@uoguelph.ca)
}

Recebido em 20 de março de 2017; aceito em 08 de junho de 2018

\section{Resumo}

Um teste de bombeamento com 171 horas de duração e vazão constante foi realizado no Sistema Aquífero Guarani (SAG) para obter seus parâmetros hidráulicos e testar a existência de drenança através de um pacote de 84 metros de basalto do Aquitarde Serra Geral, que o recobre, e através dos sedimentos da Formação Corumbataí, sotoposta a ele. O ensaio foi realizado em um poço de bombeamento com monitoramento da carga hidráulica em dois piezômetros multiníveis, localizados no Distrito de Bonfim Paulista, pertencente ao município de Ribeirão Preto, São Paulo, e situado $10 \mathrm{~km}$ ao sul da área urbana dessa cidade. Os resultados indicaram a inexistência de drenança; e o rebaixamento do nível de água registrado nas duas direções distintas em que os piezômetros com filtros no SAG foram instalados em relação ao poço de bombeamento permitiu determinar a existência de anisotropia da condutividade hidráulica. Os parâmetros hidráulicos obtidos com esse ensaio, após correção dos dados para penetração parcial do poço de bombeamento e presença de anisotropia, foram a condutividade hidráulica de $5,3 \times 10^{-6}$ e $8,1 \times 10^{-6} \mathrm{~m} / \mathrm{s}$, e o coeficiente de armazenamento de $1,6 \times 10^{-3}$ e 8,4 $\times 10^{-4}$ para os piezômetros PPE-1G e PPE-2G, respectivamente. A orientação do eixo com maior valor de transmissividade $\left(\mathrm{T}_{\mathrm{x}}=1,9 \times 10^{-3} \mathrm{~m}^{2} / \mathrm{s}\right)$ é $\mathrm{N}-\mathrm{S}$, e a de menor $\left(\mathrm{T}_{y}=1,2 \times 10^{-3} \mathrm{~m}^{2} / \mathrm{s}\right)$ é E-W. No plano horizontal, a relação entre esses valores é de 1,55 . A ausência de estabilização do nível de água durante o bombeamento no SAG indica que a drenança é insignificante ou inexistente, tanto nos basaltos quanto através da Formação Corumbataí.

Palavras-chave: Sistema Aquífero Guarani; Teste de bombeamento; Confinamento; Anisotropia; Ribeirão Preto.

\begin{abstract}
A constant-rate pumping test executed during $171 \mathrm{~h}$ in the Guarani Aquifer System (GAS) was used to determine its respective hydraulic parameters and to test the existence of a drainage through an 84-m basalt layer (Serra Geral Aquitard), and the underlying sediments of the Corumbataí Formation. The test was prformed in a pumping well with hydraulic load monitoring in two minucipalities of Ribeirão Preto (São Paulo State, Brazil), located $10 \mathrm{~km}$ south of it. Results show a lack of drainage, and the positioning of the piezometers, in two distinct directions relative to the pumping well, allowed to infer the existence of anisotropy of the hydraulic conductivity. The calculated hydraulic parameters, after data correction for the pumping well's partial penetration and for the aquifer's anisotropy, are a hydraulic conductivity of $5,3 \times 10^{-6} \mathrm{~m} / \mathrm{s}$ and $8,1 \times 10^{-6} \mathrm{~m} / \mathrm{s}$, and storativity of $1,6 \times 10^{-3}$ e $8,4 \times 10^{-4}$, respectively for piezometers PPE-1G and PPE-2G. Maximum transmissivity, $\mathrm{T}_{\mathrm{x}}=1,9 \times 10^{-3} \mathrm{~m}^{2} / \mathrm{s}$, occurs along the N-S direction, and minimum transmissivity, $\mathrm{T}_{\mathrm{y}}=1,2 \times 10^{-3} \mathrm{~m}^{2} / \mathrm{s}$, sits along the E-W direction. On the horizontal plane, the relation between maximum and minimum transmissivities is 1,55. Drawdown does not stabilize during pumping, indicating that leakage through the basalts and through Corumbatai Formation was not sufficient to compensate for the discharge, or is nonexistent.
\end{abstract}

Keywords: Guarani Aquifer System; Pumping Test; Confinement; Anisotropy; Ribeirão Preto. 


\section{INTRODUÇÃO}

O Sistema Aquífero Guarani (SAG) é um dos maiores aquíferos do planeta e estende-se por quatro países: Argentina, Brasil, Paraguai e Uruguai. Cobre uma área de 1.087.879 $\mathrm{km}^{2}$ da porção meridional da América do Sul (OEA, 2009), tendo sido por esse motivo também denominado de Sistema Aquífero Mercosul por Araújo et al. (1999). Dada a sua grande importância, o SAG foi objeto de vários estudos em grande escala nos últimos anos, como o "Projeto para a Proteção Ambiental e Desenvolvimento Sustentável do Sistema Aquífero Guarani" (PSAG), financiado pela Global Environmental Facility (GEF) (Foster et al., 2009). Pela mesma razão, o SAG foi objeto de estudos realizados pelo Instituto de Pesquisas Tecnológicas do Estado de São Paulo e Coordenadoria de Planejamento Ambiental (IPT e CPLA, 2011) e contratados pela Agência Nacional de Águas (concorrência ${ }^{\circ}$ 004/ANA/2011), nos quais se buscou avançar nas proposições de proteção e conservação do manancial. No Brasil, o SAG é composto das formações Botucatu e Piramboia, sendo confinado na base pelos sedimentos do Grupo Passa Dois e no topo pelos basaltos da Formação Serra Geral. Esses basaltos recobrem cerca de $80 \%$ da área do SAG.

A água do SAG abastece parcial ou totalmente por volta de 500 cidades no Brasil (Foster et al., 2009; Hirata et al., 2015). Entre os centros urbanos totalmente abastecidos por sua água está Ribeirão Preto, com população estimada em mais de 660 mil habitantes (IBGE, 2016). O volume de água extraído causa depleção continuada, gerando rebaixamento acentuado dos níveis potenciométricos (NP) do SAG na zona urbana do município. Dados históricos dos NP mostram queda acentuada a partir da metade da década de 1970. Em um dos poços, a diferença observada de nível de água entre 1983 e 1997 atinge 40 metros (Blöcher, 2004). Isso faz com que o NP do SAG fique abaixo daquele observado para o Aquitarde Serra Geral (ASG), invertendo a tendência natural de fluxo, que deveria ser ascendente por conta do gradiente piezométrico original entre as unidades, para descendente, o que aumenta o risco de contaminação por atividades antrópicas (Iritani et al., 2004). Iritani (2004) detectou concentrações elevadas de nitrato e cloreto em poços no SAG no interior da área urbana de Ribeirão Preto e concluiu que a contaminação ocorre por decorrência de atividades antrópicas realizadas sem os devidos cuidados na superfície do terreno, ou proximidades da boca de poços, o que resulta na infiltração de substâncias indevidas no SAG, ou através dos próprios poços, ou através de fraturas transmissivas nos basaltos do ASG. Gallo e Sinelli (1980) já haviam sugerido a existência de zonas fraturadas no basalto, passíveis de permitir a recarga do SAG. Diante desse contexto, os principais objetivos do presente trabalho foram:

- determinar os parâmetros hidráulicos do SAG;
- testar a existência de drenança através do ASG, com teste de bombeamento de vazão constante, utilizando piezômetros multiníveis para monitoramento do nível de água.

\section{LOCALIZAÇÃO E CONTEXTO GEOLÓGICO}

A área de estudo localiza-se na Chácara Esmeralda, Distrito de Bonfim Paulista, $9 \mathrm{~km}$ ao sul do centro da cidade de Ribeirão Preto (23k 211284 m E, e 7646692 m S), nordeste do estado de São Paulo (Figura 1).

A região de Ribeirão Preto está localizada na borda leste da Bacia do Paraná, na qual se observa a ocorrência das formações Botucatu (Jurássico-Cretáceo) e Piramboia (Permo-Triássico), que, agrupadas, constituem o SAG no estado de São Paulo. A Formação Botucatu é constituída de arenitos com estratificações cruzadas, planares ou acanaladas, de médio a grande porte, originadas em campos de dunas eólicas, com raras intercalações de arenitos com estratificações plano paralelas associadas a interdunas secas (Assine et al., 2004). A Formação Piramboia é constituída por arenitos com estratificação cruzada de médio porte, cruzada de baixo ângulo e plano-paralela, e com lâminas ricas em argila ou silte, depositados em ambiente de interação fluvio-eólica (campos de dunas e interdunas úmidas de ambiente desértico), bem como arenitos conglomeráticos de fácies de canais fluviais (Caetano-Chang e Wu, 1992; Milani et al., 1994; Caetano-Chang, 1997). Desnivelamentos verticais do contato das formações Corumbataí e Piramboia são sugeridos, com dúvidas, para parte da seção geológica, com base em Massoli (2007) e Fernandes et al. (2010), conforme indicado pelos pontos de interrogação presentes na porção central da seção geológica apresentada na Figura 1.

O SAG é sotoposto pelos argilitos e arenitos finos do topo da Formação Corumbataí (Permiano) (Perrotta et al., 2005) e sobreposto pelos basaltos da Formação Serra Geral (Eocretáceo). Na área de estudo, conforme mapeamento de detalhe de Fernandes et al. (2010, 2016), essa formação é composta de quatro derrames de basaltos, denominados, da base para o topo, de B1 (diretamente superposto aos arenitos Botucatu), B2, B3 e B4. B1 e B2 apresentam espessura de 40 a $60 \mathrm{~m}$ e B3, de 80 a $100 \mathrm{~m}$, sendo que B4 foi, em grande parte, erodido. Finas camadas de arenitos intertrap ocorrem descontinuamente entre B1 e B2 e entre B2 e B3. A coleta de amostras de calha, durante a perfuração de poços de observação (piezômetros) próximos ao poço testado, Poço Esmeralda (PE), permitiu verificar que, nesse local, B1 apresenta $48 \mathrm{~m}$ de espessura, com $25 \mathrm{~m}$ de camada vesicular no topo, e B2, parcialmente erodido, apresenta $45 \mathrm{~m}$, sobreposto por $8 \mathrm{~m}$ de solo e rocha muito alterada. Abaixo de B1, esse poço secciona aproximadamente $55 \mathrm{~m}$ da Formação Botucatu. 


\section{CONTEXTO HIDROGEOLÓGICO}

No estado de São Paulo, o SAG possui faixa aflorante, de largura irregular, inserida na Depressão Periférica na porção central, sul e norte, ocupando faixa de direção aproximada $\mathrm{N}-\mathrm{S}$, nas regiões das cidades de Piracicaba, Araraquara e Ribeirão Preto. A oeste dessa faixa, encontra-se confinado pelos basaltos do ASG, numa extensão de cerca de 174 mil $\mathrm{km}^{2}$. Nessa região, as águas do $\mathrm{SAG}$ abastecem cidades importantes tais como São José do Rio Preto, Presidente Prudente, Marília e Araçatuba (Sracek e Hirata, 2002; Hirata et al., 2011). Os gradientes da superfície de contato com o ASG são de $0,0018 \mathrm{~m} / \mathrm{m}$ ao longo do vale do Rio Tietê, e de $0,0038 \mathrm{~m} / \mathrm{m}$, ao longo do eixo próximo ao Rio do Peixe até as imediações da cidade de Avaré (Takahashi, 2005). A espessura do SAG varia de aproximadamente $100 \mathrm{~m}$ na área aflorante até mais de $400 \mathrm{~m}$, a oeste, ao final da extremidade oeste da calha do Rio Tietê.
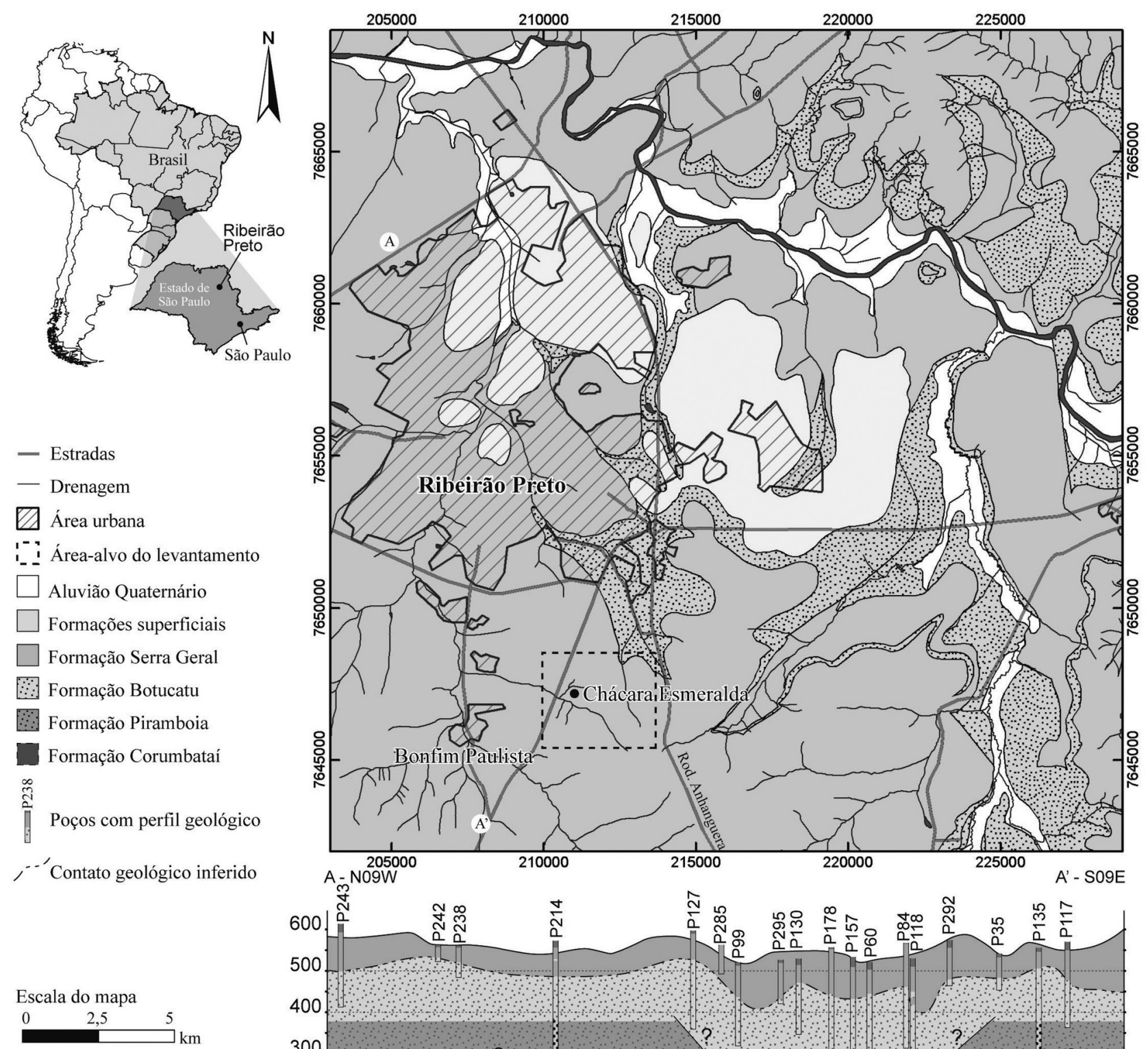

Escala da seção geológica $\begin{array}{lll}0 & 1 & 2 \\ 2 & & k m\end{array}$

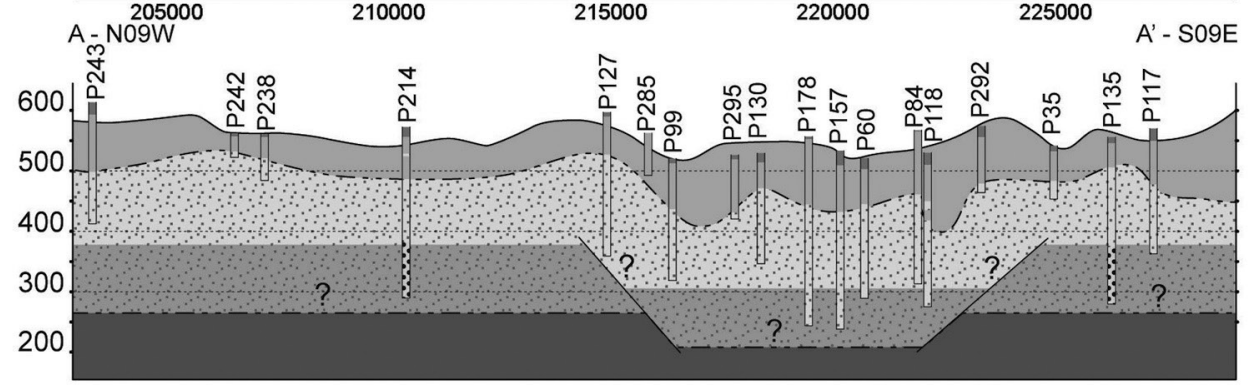

Fonte: baseado em Sinelli (1973) e em dados de poços.

Figura 1. Localização da área de estudo na Chácara Esmeralda, a sul da zona urbana de Ribeirão Preto. 
Os parâmetros hidráulicos médios do SAG foram obtidos com base em dados de 111 poços selecionados (Takahashi, 2005). A geometria das equipotenciais indica fluxo regional de leste para sudoeste, com gradiente hidráulico médio de aproximadamente $0,001 \mathrm{~m} / \mathrm{m}$ na porção confinada, e de 0,003 a $0,008 \mathrm{~m} / \mathrm{m}$ na área aflorante.

Os valores médios de condutividade hidráulica $(\mathrm{K})$ do SAG, obtidos pelo cálculo da média ponderada, em função das espessuras, dos valores de $\mathrm{K}$ das formações Piramboia $\left(2,9 \times 10^{-5} \mathrm{~m} / \mathrm{s}\right)$ e Botucatu $\left(4,1 \times 10^{-5} \mathrm{~m} / \mathrm{s}\right)$ (DAEE, 1974), são $3,0 \times 10^{-5} \mathrm{~m} / \mathrm{s}$ para a área confinada $\mathrm{e}$ $3,5 \times 10^{-5} \mathrm{~m} / \mathrm{s}$ para a área livre. Da mesma forma, o coeficiente de armazenamento (S) da porção livre é de 0,17 , média ponderada considerando um valor médio de $\mathrm{S}$ de 0,15 para a Formação Piramboia (DAEE, 1974) e 0,25 para a Formação Botucatu (Silva, 1983); na porção confinada, o S é de $10^{-3}$. A transmissividade (T), obtida com base no mapa de espessura do aquífero e nos valores de $\mathrm{K}$, é de aproximadamente $3 \times 10^{-3} \mathrm{~m}^{2} / \mathrm{s}$ na área aflorante, aumentando progressivamente para oeste até atingir valores superiores a $1,4 \times 10^{-2} \mathrm{~m}^{2} / \mathrm{s}$ ao longo do vale do Rio Tietê, na área confinada. As vazões (Q) de poços, recomendadas por Takahashi (2005), variam de $6 \times 10^{-3} \mathrm{a}$ $2 \times 10^{-2} \mathrm{~m}^{3} / \mathrm{s}$, no sistema livre, e de $2 \times 10^{-2}$ a $1 \times 10^{-1} \mathrm{~m}^{3} / \mathrm{s}$, no sistema confinado.

Paula e Silva et al. (2008) separam o SAG em quatro hidrofácies na cidade de Ribeirão Preto, com base em perfilagens geofísicas, sendo três (A, B e C, da base para o topo) na Formação Piramboia e uma (D) na Formação Botucatu. A hidrofácies A apresenta sedimentos arenosos finos, com elevado conteúdo de argila, gerando, segundo os autores, redução do $\mathrm{K}$ do pacote, que atinge espessura máxima de $106 \mathrm{~m}$. A hidrofácies $\mathrm{B}$, com espessura média de $80 \mathrm{~m}$, é formada por corpos arenosos de granulometria crescente e diminuição do conteúdo de argila da base para o topo, chegando a conglomeráticos. A hidrofácies $\mathrm{C}$ possui espessura máxima de $32 \mathrm{~m}$ e é composta de arenitos finos a muito finos, argilosos, indicativos de baixa permoporosidade, segundo os autores.

\section{REVISÃO BIBLIOGRÁFICA: ANISOTROPIA EM AQUÍFEROS SEDIMENTARES}

A anisotropia é definida pela existência de diferentes valores de $\mathrm{K}$, dependendo da direção da medição feita, em um mesmo ponto (Freeze e Cherry, 1979). Várias situações podem causar anisotropia. Bear (1979) descreve o exemplo de micas depositadas na formação que compõe o aquífero, de forma a resultar em permeabilidades maiores na direção horizontal. $\mathrm{O}$ autor ainda cita que tanto o processo sedimentar quanto a compressão causada pela contínua deposição do pacote sedimentar sobrejacente fazem com que os grãos fiquem com seus eixos maiores orientados paralelamente ao plano de deposição, gerando posteriormente planos de fluxo preferencial paralelos ao acamamento e, consequentemente, à anisotropia. A deposição sequencial de camadas de distintas permeabilidades também pode gerar anisotropia, porém Bear (1979) aponta que uma formação estratificada de qualquer tipo só pode ser considerada como equivalente a um aquífero anisotrópico quando a espessura das camadas depositadas for muito menor do que a escala de interesse do trabalho.

Muitos autores abordaram a questão da anisotropia, a influência da escala de trabalho e o desenvolvimento de métodos para sua determinação em solos, aquíferos e reservatórios de petróleo (e.g., Moore, 1979; Ahuja et al., 1984; Anderson, 1989; Bjerg et al., 1992; Burger e Belitz, 1997). No caso dos aquíferos, uma motivação frequente para a determinação da anisotropia é a necessidade de estabelecer os parâmetros relevantes para o transporte de solutos em casos de contaminação (e.g., Anderson, 1989; Bjerg et al., 1992), porém poucos autores se debruçaram sobre a existência de anisotropia em arenitos de origem eólica. Lindquist (1988), analisando os sedimentos da Formação Nugget, nos Estados Unidos, determinou que a direção de maior permeabilidade é horizontal, paralela às estratificações cruzadas, e a de permeabilidade menor é ortogonal às estratificações (Figura 2). Van den Berg e Vries (2003) realizaram uma sequência detalhada de ensaios em várias fácies associadas a dunas na Holanda, usando diferentes métodos como permeâmetros, análise granulométrica e simulação de fluxo por análise de imagens de seções delgadas dos sedimentos. Na fácies associada a dunas eólicas, também determinaram a existência de anisotropia. Os valores de anisotropia entre o $\mathrm{K}_{\text {min. }}$ e $\mathrm{K}_{\text {máx. }}$ obtidos por Van den Berg e Vries (2003) na fácies eólica, com alto grau de arredondamento e boa seleção dos grãos, foi de até 1,45. Lindquist (1988) obteve permeabilidade horizontal $\left(\mathrm{k}_{\mathrm{h}}\right)$ de $1,3 \times 10^{-6} \mathrm{~m} / \mathrm{s}$, e vertical $\left(\mathrm{k}_{\mathrm{v}}\right)$ de $1,9 \times 10^{-6} \mathrm{~m} / \mathrm{s}$ em estruturas de fluxo de grãos de paleodunas eólicas, sem influência de deposição subaquosa ou superfícies erosivas. Isso representa uma anisotropia de $1,46\left(\mathrm{k}_{\mathrm{h}} / \mathrm{k}_{\mathrm{v}}\right)$.

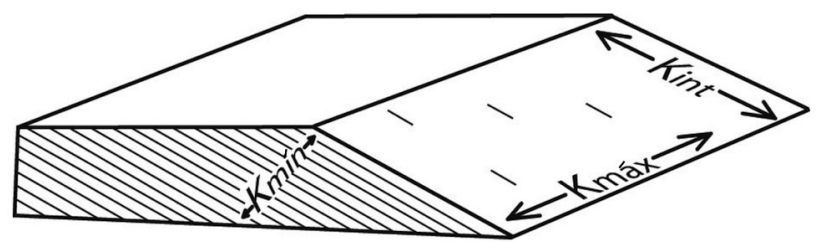

Fonte: adaptado de Lindquist (1988).

Figura 2. Distribuição das orientações de condutividade hidráulica máxima $\left(\mathrm{K}_{\text {máx }}\right)$, intermediária $\left(\mathrm{K}_{\mathrm{int}}\right)$ e mínima $\left(\mathrm{K}_{\text {min }}\right)$ com relação aos planos de estratificação de paleodunas eólicas. 


\section{MATERIAIS E MÉTODOS}

\section{Campo de poços Esmeralda}

A área de estudo localiza-se fora da zona de influência do cone de rebaixamento existente na mancha urbana de Ribeirão Preto. Estudos para definir a geometria do aquífero, do aquitarde e investigar a presença de possíveis zonas de fraturas tectônicas no basalto precederam a escolha do poço a ser usado para o teste de bombeamento. Esses estudos incluíram levantamentos geofísicos (sondagens elétricas verticais, caminhamentos elétricos e método áudio magneto-telúrico com fonte controlada - CSAMT), descrição de afloramentos e levantamento de informações de poços existentes. Os resultados desses levantamentos estão disponíveis em Wahnfried (2010) e Fernandes et al. (2010, 2011, 2016).

Para a realização do teste de bombeamento foi escolhido um poço de produção desativado, distante de outros poços que explotam o SAG, denominado de Poço Esmeralda (PE), com $152 \mathrm{~m}$ de profundidade. Com os objetivos de conhecer o perfil construtivo do poço e de verificar o seu estado de conservação, foi realizada filmagem das suas paredes e, posteriormente, a sua limpeza. A turbidez da água impediu a filmagem abaixo de $112 \mathrm{~m}$ de profundidade, de modo que apenas a localização e a extensão da primeira seção filtrante são conhecidas. As demais seções filtrantes foram inferidas com base em informações verbais do proprietário, que acompanhou a sua perfuração. A posição dos filtros também permitiu inferir que a espessura de basalto se estende, aproximadamente, até a profundidade de $95 \mathrm{~m}$. Próximo ao PE foram construídos dois poços piezômetros multiníveis, PPE-1 e PPE-2, a distâncias de 15,0 e 22,2 m, com relação ao PE, respectivamente (Figura 3). Seu posicionamento permitiu investigar as propriedades do aquífero em diferentes direções.

Os piezômetros foram construídos a pequenas distâncias com relação ao PE para aumentar a chance de haver reflexo do cone de rebaixamento no SAG na potenciometria do ASG. O método usado para a construção dos piezômetros foi o roto-percussivo. Em ambos, a perfuração foi interrompida antes de alcançar o SAG para a realização de perfilagem acústica, com o intuito de localizar e determinar a atitude das fraturas existentes no basalto. Após as perfilagens, os poços foram aprofundados ainda com sondas roto-percussivas, penetrando o SAG. Como nesse método não é usada lama de perfuração, as paredes do furo no arenito colapsaram, reduzindo a penetração dos piezômetros no SAG, sobretudo no PPE-1. Após a inserção dos tubos de PVC geomecânico de $50 \mathrm{~mm}$ de diâmetro que constituem os piezômetros, foi colocado pré-filtro, preenchendo o espaço anelar dentro da Formação Botucatu. Selos de bentonita foram utilizados para isolar os piezômetros do SAG daqueles do ASG. O topo dos selos foi posicionado de modo a não obstruir as fraturas do basalto observadas nas perfilagens acústicas, com espessura de $5 \mathrm{~m}$ no PPE-1 e de 8 m no PPE-2. Acima dos selos, o espaço anelar ficou aberto (Figura 4).

Também foram construídos dois piezômetros rasos ao lado do PE, denominados PME-1 e PME-2, com 4,0 e 5,4 m de profundidade, respectivamente, para monitorar o nível freático na camada de solo e basalto intemperizado. Os dados construtivos são apresentados na Tabela 1.

\section{Execução do teste de bombeamento e interpretação dos dados}

Durante o teste de bombeamento, as medições de nível dinâmico foram realizadas em todos os pontos disponíveis no SAG (PE, PPE-1G, PPE-2G, PME-1 e PME-2). O monitoramento dos piezômetros no ASG indicou que o nível de água não estabilizou desde sua construção até a execução do teste de bombeamento, fazendo com que os dados não pudessem ser utilizados. No PE, a medição foi feita por meio de um transdutor de pressão Druck, modelo PTX-1830, com fundo de escala de $30 \mathrm{~m}$ de coluna d'água, conectado a um registrador de dados Campbell, modelo CR-10X. As medições em todos os piezômetros foram feitas manualmente, usando dois medidores de nível da marca Heron, de 100 e $200 \mathrm{~m}$ de comprimento, e um da marca Hidrosuprimentos, de $100 \mathrm{~m}$. No início, as medições foram feitas com elevada frequência, passando-se a utilizar intervalos de medição mais espaçados com o avanço do teste.

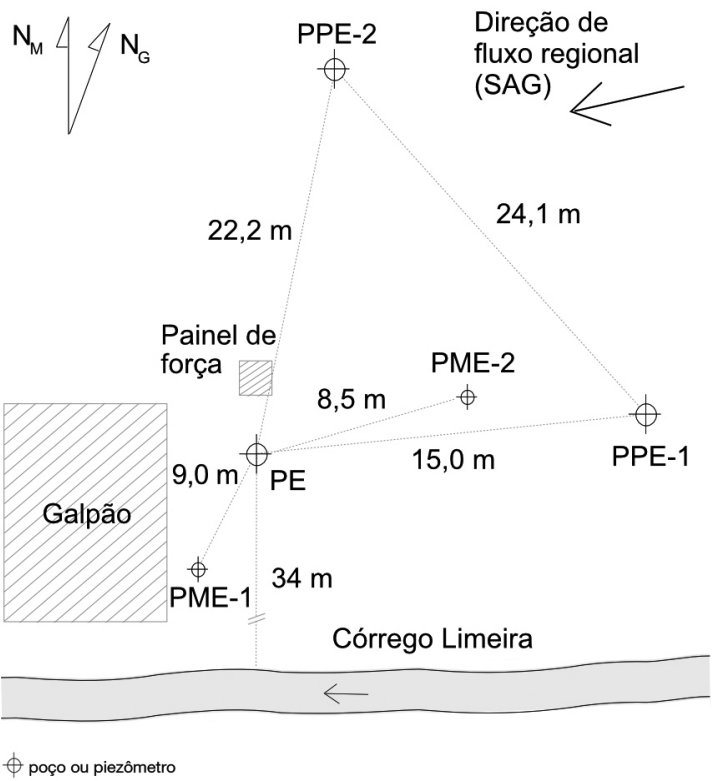

$\mathrm{N}_{\mathrm{M}}$ : norte magnético; $\mathrm{N}_{\mathrm{G}}$ : norte geográfico; SAG: Sistema Aquífero Guarani; PPE: poços com piezômetros profundos; PME: piezômetros rasos; PE: Poço Esmeralda.

Figura 3. Mapa esquemático de localização do poço e piezômetros na Chácara Esmeralda. 


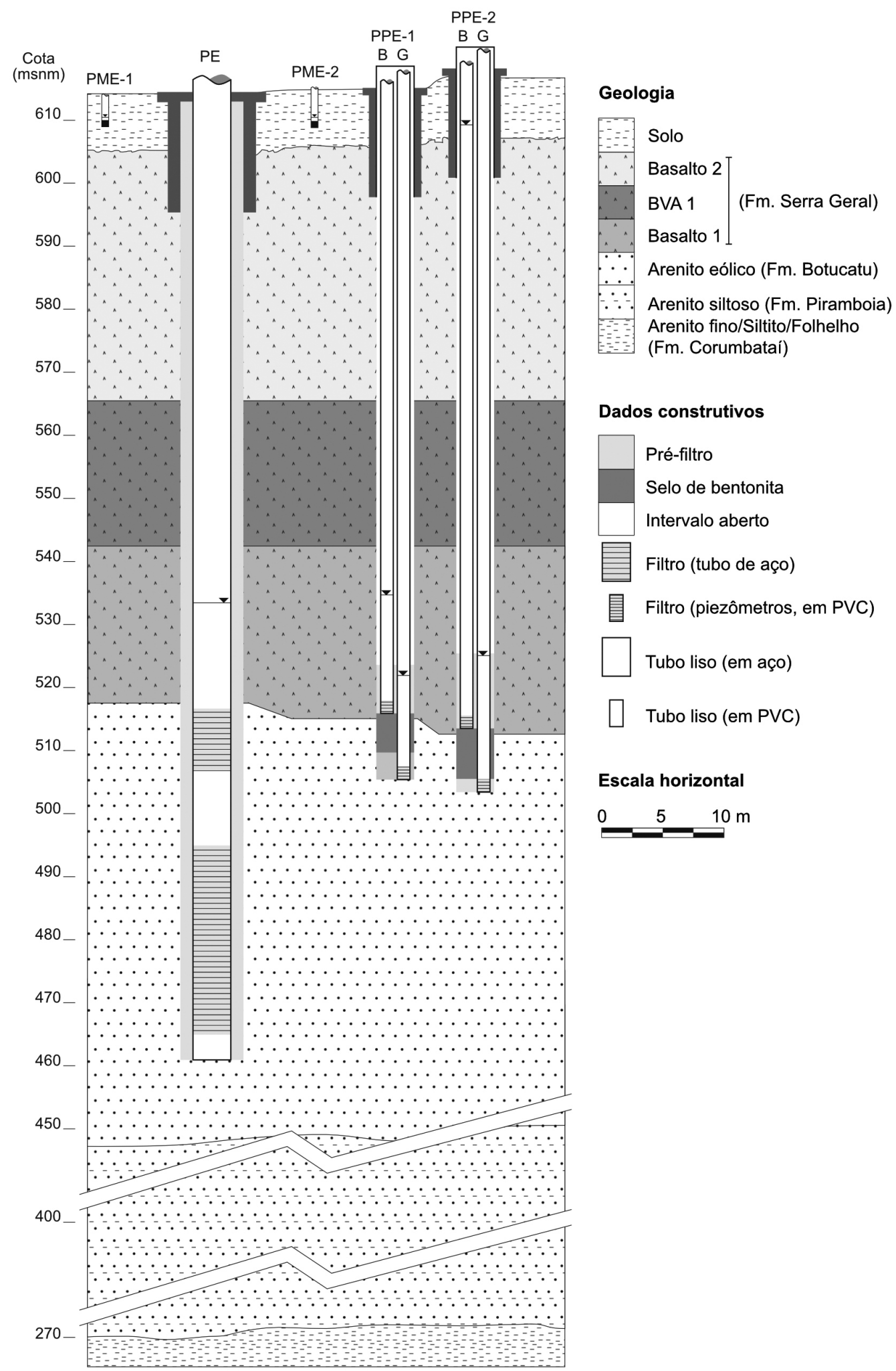

msnm: metros sobre o nível do mar; PE: Poço Esmeralda (bombeando o Sistema Aquífero Guarani); PPE: poços com piezômetros profundos (B: Aquitarde Serra Geral; G: Sistema Aquífero Guarani); PME: piezômetros rasos (solo); BVA: basalto vesicular amidaloidal; Fm.: Formação.

Figura 4. Perfis construtivos dos piezômetros e poço na Chácara Esmeralda. A distribuição em planta é apresentada na Figura 3. 
A bomba estava posicionada a $114 \mathrm{~m}$ de profundidade a partir da boca do PE. Para medir a vazão (Q) foi usado um orifício calibrado de $50 \mathrm{~mm}$, montado em tubo de $62,5 \mathrm{~mm}$. A água bombeada foi direcionada para uma caixa d'água de $1.000 \mathrm{~L}$, e dessa para o Córrego Limeira, a aproximadamente $40 \mathrm{~m}$ do local bombeado. Antes do início do teste de $\mathrm{Q}$ constante, foi realizado um bombeamento escalonado para determinar a vazão ideal a ser utilizada, de $29 \mathrm{~m}^{3} / \mathrm{h}$.

Os dados de rebaixamento em função do tempo obtidos com o teste não se ajustam à curva-tipo de Theis, em razão da penetração parcial do poço de bombeamento. $\mathrm{OPE}$ possui aproximadamente $46 \mathrm{~m}$ de filtros, e o SAG deve ter cerca de $230 \mathrm{~m}$ de espessura no local definido por Massoli (2007), valor próximo às espessuras somadas das três hidrofácies superiores, e mais permeáveis, do SAG descritas por Paula e Silva et al. (2008). Por causa da baixa penetração dos filtros do PE, foi utilizado o método de interpretação de testes de bombeamento de Hantush (1961a, 1961b), uma adaptação do método de Theis para poços não totalmente penetrantes, em aquíferos confinados e isotrópicos, descrito pelas Equações 1 a 8 (Kruseman e de Ridder, 1991), com as variáveis explicadas a seguir e apresentadas na Figura 5:

$$
\begin{aligned}
& S=\frac{Q}{8 \pi K(b-d)} E\left(u, \frac{b}{r}, \frac{d}{r}, \frac{a}{r}\right) \\
& E\left(u, \frac{b}{r}, \frac{d}{r}, \frac{a}{r}\right)=M\left(u, B_{1}\right)-M\left(u, B_{2}\right)+M\left(u, B_{3}\right)-M\left(u, B_{4}\right) \\
& u=\frac{r^{2} S_{s}}{4 K t} \\
& B_{1}=(b+a) / r \\
& B_{2}=(d+a) / r \\
& B_{3}=(b-a) / r
\end{aligned}
$$

$B_{4}=(d-a) / r$

$M(u, B)=\int_{u}^{\infty} \frac{e^{-y}}{y} \operatorname{erf}(B \sqrt{y}) d y$

Em que:

$\mathrm{s}=$ rebaixamento $(\mathrm{m})$;

$\mathrm{Q}=\operatorname{vazão}\left(\mathrm{m}^{3} / \mathrm{s}\right)$;

$\mathrm{K}=$ condutividade hidráulica $(\mathrm{m} / \mathrm{s})$;

$\mathrm{r}=$ distância do poço de bombeamento ao piezômetro (m);

$\mathrm{S}_{\mathrm{s}}=$ armazenamento específico do aquífero $(1 / \mathrm{m})$;

$\mathrm{t}=$ tempo decorrido de bombeamento (s);

$\mathrm{M}(\mathrm{u}, \mathrm{B})=$ os valores dessas funções são tabelados e apresentados, por exemplo, no anexo 10.2 de Kruseman e de Ridder (1991).

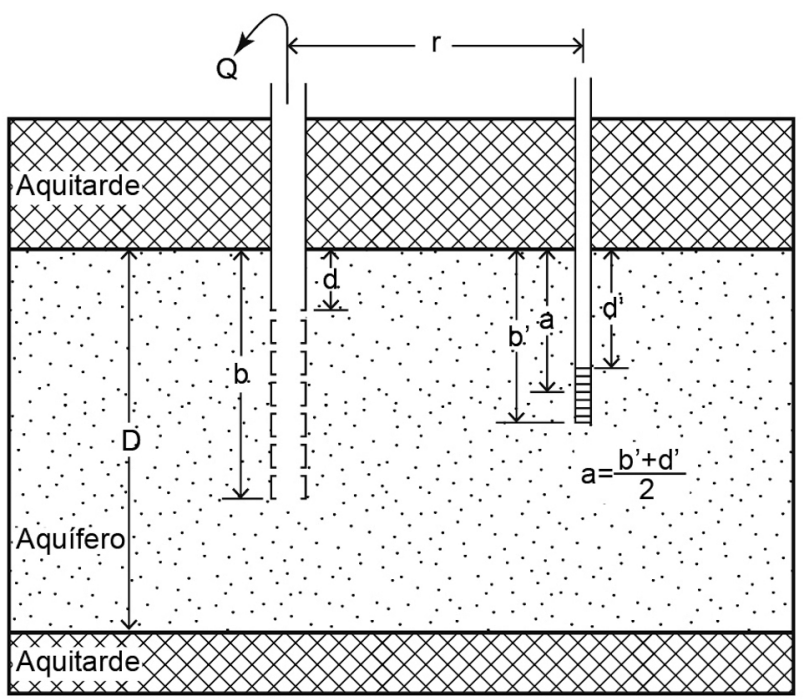

\begin{tabular}{|c|c|c|c|c|c|}
\hline & $\mathrm{PE}$ & PPE-1 & PPE-2 & PME-1 & PME-2 \\
\hline Profundidade total (m) & 152 & $\begin{array}{l}B=88,0 \\
G=98,5\end{array}$ & $\begin{array}{c}B=92,6 \\
G=102,8\end{array}$ & 4,0 & 5,4 \\
\hline Diâmetro do tubo de revestimento (mm) & 150 & 50 (furo: 150) & 50 (furo: 200) & 25 & 25 \\
\hline Extensão do filtro (m) & $46^{\star}$ & $B=2 ; G=2$ & $B=2 ; G=2$ & 1 & 1 \\
\hline Espessura de solo (m) & ND & 15 & 16 & - & - \\
\hline Espessura de basalto (m) & ND & 82 & 84 & - & - \\
\hline Penetração no SAG (m) & $56^{\star}$ & 0,6 & 2,1 & - & - \\
\hline
\end{tabular}

Fonte: traduzido de Kruseman e de Ridder (1991).

Figura 5. Variáveis espaciais utilizadas nas equações de Hantush (1961a, 1961b), em que $Q$ = vazão.

Tabela 1. Dados construtivos do Poço Esmeralda, poços com piezômetros e dos poços de monitoramento do aquífero freático. Todas as profundidades são medidas a partir da boca dos respectivos tubos.

PE: Poço Esmeralda; PPE-1 e PPE-2: poços com piezômetros profundos; PME-1 e PME-2: piezômetros rasos; B: piezômetro no basalto; G: piezômetro no Sistema Aquífero Guarani; *estimado com base na filmagem e em informações fornecidas pelo proprietário; ND: não determinado; SAG: Sistema Aquífero Guarani. 
Para fazer a correção para a existência de anisotropia no plano horizontal em aquíferos confinados, foi utilizado o método de Hantush (1966). O autor se baseou na equação de Theis (1935) para calcular os parâmetros hidráulicos coeficiente de armazenamento $\mathrm{S}$ e transmissividade em direções específicas $\left(\mathrm{T}_{\mathrm{n}}\right)$, por meio das Equações 9 a 15 (Kruseman e de Ridder, 1991):

$$
\begin{aligned}
& s=\frac{Q}{4 \pi T_{e}} W\left(u_{x y}\right) \\
& u_{x y}=\frac{r^{2} S}{4 t T_{n}} \\
& T_{e}=\sqrt{T_{x} \times T_{y}} \\
& T_{n}=\frac{\cos ^{2}\left(\theta+\alpha_{n}\right)+m \operatorname{sen}^{2}\left(\theta+\alpha_{n}\right)}{m^{2}}=\frac{\alpha_{n} \cos ^{2} \theta-\cos ^{2}\left(\theta+\alpha_{n}\right)}{\operatorname{sen}^{2}\left(\theta+\alpha_{n}\right)-\alpha_{n} \operatorname{sen}^{2} \theta} \\
& m=\frac{T_{x}}{T_{y}}=\left(\frac{T_{e}}{T_{y}}\right)^{2} \\
& a_{n}=\frac{T_{1}}{T_{n}}
\end{aligned}
$$

Em que:

$s=$ rebaixamento $(\mathrm{m})$;

$S=$ coeficiente de armazenamento (adimensional);

$Q=$ vazão $\left(\mathrm{m}^{3} / \mathrm{s}\right)$;

$r=$ distância do piezômetro ao poço de bombeamento (m);

$t=$ tempo de bombeamento (s);

$q$ = ângulo formado entre a direção de maior transmissividade (x) e o piezômetro mais próximo a essa direção (Figura 6); $a_{\mathrm{n}}=$ ângulo formado entre piezômetros (Figura 6);

$W\left(u_{\mathrm{XY}}\right)=$ função de poço de Theis, também denominado rebaixamento adimensional, adaptado para aquífero anisotrópico; $u_{\mathrm{XY}}=$ argumento da função de poço de Theis, também denominado tempo adimensional, adaptado para aquífero anisotrópico;

$T_{e}=$ transmissividade efetiva, apresentada na Equação $16\left(\mathrm{~m}^{2} / \mathrm{s}\right)$;

$T_{\mathrm{x}}^{e}=$ maior transmissividade do aquífero $\left(\mathrm{m}^{2} / \mathrm{s}\right)$ (eixo $\mathrm{x}$ da Figura 6);

$T_{\mathrm{y}}=$ menor transmissividade do aquífero $\left(\mathrm{m}^{2} / \mathrm{s}\right)$ (eixo y da Figura 6);

$m=$ relação entre a maior e a menor transmissividade;

$T_{n}=$ transmissividade calculada nas direções dos piezômetros; na Figura 6, $T_{1}$ está na direção do piezômetro 1 e $T_{2}$, na direção do piezômetro 2 ; $a_{\mathrm{n}}=$ relação entre a transmissividade calculada com dados do piezômetro 1 e de um piezômetro $n$ (qualquer), sendo que $a_{1}=1$ por gerar a divisão entre dois valores iguais $\left(T_{1} / T_{1}\right)$.

Hantush (1966) menciona que a transmissividade efetiva $\left(\mathrm{T}_{\mathrm{e}}\right)$ deve ser obtida por intermédio da aplicação de métodos de interpretação comuns, e ser então corrigida para considerar a existência de anisotropia. $\mathrm{O}$ autor ressalta que a $\mathrm{T}_{\mathrm{e}}$ deve ser semelhante para os dados de todos os piezômetros, independentemente de sua direção em relação ao poço de bombeamento, e mostra um exemplo no qual considera a diferença de um terço nos valores de T como sendo admissível. Nesses casos, afirma que $\mathrm{o}$ valor de $\mathrm{T}_{\mathrm{e}}$ a ser usado é a média dos valores calculados para os diferentes piezômetros, conforme indicado na Equação 16 para o caso em que há dois piezômetros.

$T_{e}=\left(T_{1}+T_{2}\right) / 2$

Em que:

$T_{\mathrm{e}}=$ transmissividade efetiva $\left(\mathrm{m}^{2} / \mathrm{s}\right)$;

$T_{1}^{e}=$ transmissividade na direção 1 , com ângulo $q$ em relação à maior transmissividade $\left(\mathrm{T}_{\mathrm{X}}\right)\left(\mathrm{m}^{2} / \mathrm{s}\right)$;

$T_{2}=$ transmissividade na direção 2 , com ângulo $a_{2}$ em relação à maior transmissividade $\left(\mathrm{T}_{\mathrm{x}}\right)\left(\mathrm{m}^{2} / \mathrm{s}\right)$.
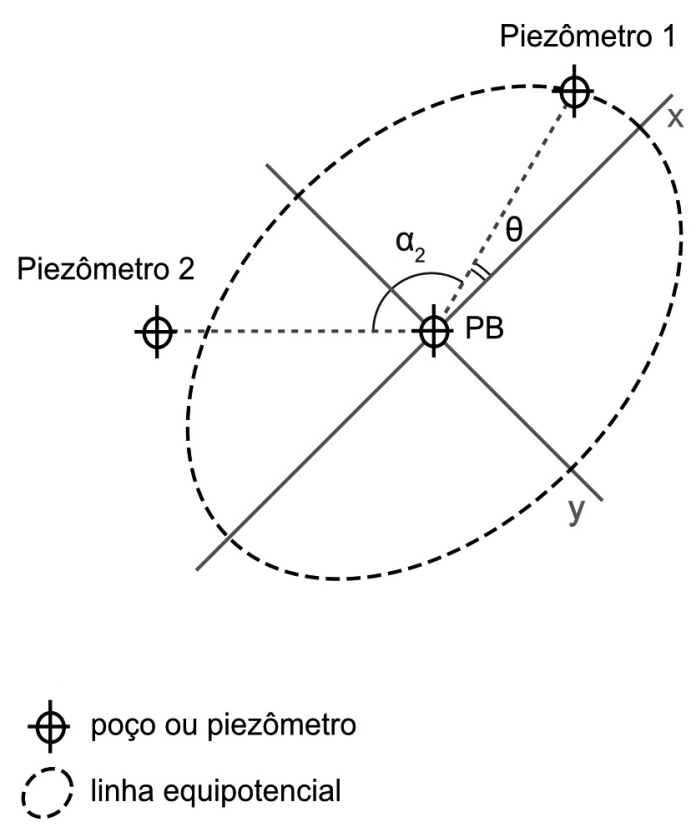

PB: poço de bombeamento; $x$ : direção de maior transmissividade do aquífero; $\mathrm{y}$ : direção de menor transmissividade do aquífero; $\theta$ : ângulo entre o eixo $x \mathrm{e}$ o piezômetro $1 ; \alpha_{2}$ : ângulo entre o piezômetro 1 e o piezômetro 2. Fonte: adaptado e traduzido de Kruseman e de Rider, (1991).

Figura 6. Ângulos utilizados no método de Hantush (1966) para determinar a magnitude da maior e da menor transmissividades em aquífero anisotrópico confinado, em que essas direções são conhecidas. 


\section{RESULTADOS E DISCUSSÃO}

Não há evidências de estabilização do nível dinâmico de água do SAG, mesmo submetido ao bombeamento de $171 \mathrm{~h}$ (Figura 7). O gráfico mono-logarítmico ressalta a diferença entre os dados de cada piezômetro. Existe um bom ajuste dos dados no tempo inicial de bombeamento, excluindo o tempo de restrição imposto pelo método (60 min para o PPE-2G e 234 min para o PPE-1G). Isso comprova que, caso exista drenança no local, ela ainda não teria sido suficiente para equilibrar a vazão bombeada. Tal interpretação é corroborada pelo fato de as condutividades hidráulicas $(\mathrm{K})$ observadas no ASG serem baixas, como demonstradas pelo período de 14 dias necessários para a recuperação dos níveis hidráulicos dos poços PPE-1B e PPE-2B e pelas grandes diferenças entre as cargas hidráulicas dos poços no ASG e SAG (Figura 4). A ausência de estabilização do SAG durante o teste de bombeamento também permite afirmar que a Formação Corumbataí, sotoposta a esse aquífero, tem contribuição muito restrita ou inexistente para sua recarga.

O método de Hantush (1961a, 1961b) para poços com penetração parcial em aquíferos confinados exige que os dados iniciais de rebaixamento não sejam utilizados na interpretação. Assim, as medições feitas durante os 60 minutos iniciais no piezômetro PPE-2G e os 234 minutos iniciais no piezômetro PPE-1G foram descartadas. Os resultados de K obtidos apresentam diferença de menos de meia ordem de magnitude entre os piezômetros: 5,1 × $10^{-6} \mathrm{~m} / \mathrm{s}$ no PPE- $1 \mathrm{G}$

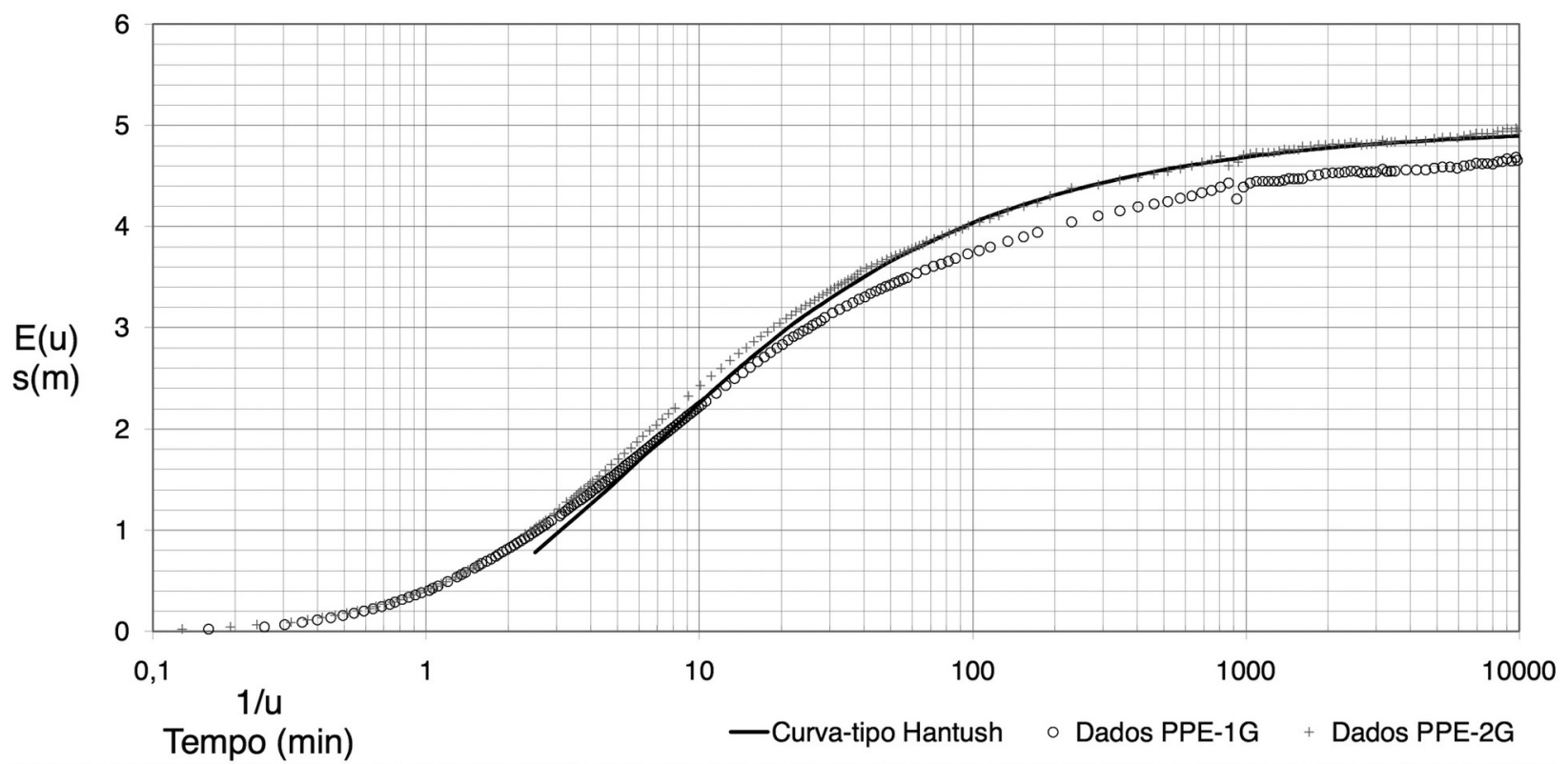

Figura 7. Dados de rebaixamento em função de tempo dos piezômetros PPE-1G e PPE-2G, com curva-tipo de Hantush (1961a, 1961b) ajustada para os dados do piezômetro PPE-2G. O autor desenvolveu um nova função de poço a partir da equação de Theis (1935), em que $E(u)$ é o rebaixamento adimensional, e o argumento 1/u é o tempo adimensional, para levar em conta a penetração parcial do poço de bombeamento. O s é o rebaixamento, em metros, medido nos piezômetros, em função de tempo, medido em minutos.

Tabela 2. Parâmetros hidráulicos recalculados para o Sistema Aquífero Guarani, considerando presença ou ausência de anisotropia.

\begin{tabular}{|c|c|c|c|c|c|}
\hline Aquífero & Direção & $\mathrm{K}(\mathrm{m} / \mathrm{s})$ & $\mathrm{T}\left(\mathrm{m}^{2} / \mathrm{s}\right)$ & Ss $(1 / \mathrm{m})$ & S (adim.) \\
\hline \multirow{3}{*}{ Anisotrópico } & PPE-1G & $5,3 \times 10^{-6 \star}$ & $1,22 \times 10^{-3}$ & $7,0 \times 10^{-6}$ & $1,6 \times 10^{-3}$ \\
\hline & $\mathrm{y}\left(\mathrm{T}_{\min }\right.$ e $\left.\mathrm{K}_{\min }\right)$ & $5,2 \times 10^{-6 *}$ & $1,20 \times 10^{-3}$ & ND & ND \\
\hline & $P P E-2 G=x\left(T_{\text {máx }}\right.$ e $\left.K_{\text {má }}\right)$ & $8,1 \times 10^{-6 *}$ & $1,85 \times 10^{-3}$ & $3,7 \times 10^{-6}$ & $8,4 \times 10^{-4}$ \\
\hline \multirow{2}{*}{ Isotrópico } & PPE-1G & $5,1 \times 10^{-6}$ & $1,18 \times 10^{-3 *}$ & $7,0 \times 10^{-6}$ & $1,6 \times 10^{-3}$ \\
\hline & PPE-2G & $7,9 \times 10^{-6}$ & $1,79 \times 10^{-3 *}$ & $3,7 \times 10^{-6}$ & $8,4 \times 10^{-4}$ \\
\hline
\end{tabular}

K: condutividade hidráulica; T: transmissividade; Ss: armazenamento específico; S (adimensional): coeficiente de armazenamento; PPE-1G: piezômetro profundo 1, com filtro no Sistema Aquífero Guarani; y $\left(\mathrm{T}_{\min }\right.$ e $\left.\mathrm{K}_{\min }\right)$ : direção y, na qual tanto a transmissividade quanto a condutividade hidráulica são mínimas; PPE-2G: piezômetro profundo 2, com filtro no Sistema Aquífero Guarani; $x\left(T_{\text {máx }}\right.$ e $\left.K_{\text {máx }}\right)$ : direção $x$, na qual tanto a transmissividade quanto a condutividade hidráulica são máximas; *valore obtidos com base em espessura do Sistema Aquífero Guarani de 230 m; ND: não determinado, uma vez que o coeficiente de armazenamento só pode ser calculado nas direções dos piezômetros. 
e $7,9 \times 10^{-6} \mathrm{~m} / \mathrm{s}$ no PPE-2G (Tabela 2). A direção com maior $\mathrm{K}$ tem maior rebaixamento por oferecer menor resistência à passagem da água. Há, portanto, evidência da existência de anisotropia ou heterogeneidade, ou mesmo ambas, no SAG nesse local, o que gerou a necessidade de reinterpretar os dados, levando em conta essa característica.

Existem diversas descrições das estruturas sedimentares da Formação Botucatu. O trabalho de maior detalhe realizado para a região de Ribeirão Preto é o de Massoli (2007). O autor encontrou, em afloramento da Formação Botucatu a 70 km de Ribeirão Preto, estratificações cruzadas tabulares de grande porte sobrepostas por arenitos com estratificações cruzadas acanaladas, também de grande porte. São, portanto, rochas análogas àquelas testadas por Lindquist (1988).

Além da anisotropia, a diferença de K poderia ser causada por heterogeneidade na rocha. Durante a perfuração dos piezômetros na Chácara Esmeralda, foi observada uma maior cimentação do arenito Botucatu no PPE-2G, fato que poderia reduzir localmente a $\mathrm{K}$, entretanto os resultados do teste de bombeamento indicam o oposto: a direção do PPE-1G possui menor $\mathrm{K}$.

Existem vários métodos de correção dos dados do teste de bombeamento para levar em conta a existência de anisotropia, mas em todos é necessário conhecer as direções de máxima e mínima $\mathrm{K}$ ou ter dados de pelo menos três piezômetros localizados em direções distintas com relação ao poço de bombeamento. Neste estudo existem apenas dois piezômetros no SAG, e não há informação geológica suficientemente detalhada para definir a orientação do elipsoide de $\mathrm{K}$ com base na estrutura dos sedimentos. A solução encontrada foi inferir indiretamente essa direção, definindo valores máximos de anisotropia para sedimentos de origem eólica, análogos ao arenito Botucatu. As características geológicas impõem um limite para as $\mathrm{K}$ possíveis. $\mathrm{O}$ valor de anisotropia entre o $\mathrm{K}_{\text {min. }}$ e $\mathrm{K}_{\text {máx }}$ obtido por Van den Berg e Vries (2003) na fácies eólica foi de até 1,45; e Lindquist (1988) obteve uma anisotropia de 1,46 comparando $\mathrm{k}_{\mathrm{h}} \mathrm{e}_{\mathrm{v}}$. Esses valores pautaram a reavaliação dos resultados dos testes aqui apresentados.

Interpolando linearmente as cotas de nível dinâmico entre os piezômetros e o PE, registrados após 169 h de bombeamento, é possível desenhar os contornos das equipotenciais, descrevendo o cone de rebaixamento. A relação entre os eixos da elipse é proporcional à relação entre os K nas direções dos eixos. Se a relação não é conhecida, a elipse pode assumir qualquer direção. $O$ fato é ilustrado na Figura 8, na qual uma equipotencial arbitrária (de $85 \mathrm{~m}$ abaixo da superfície) foi interpolada entre os piezômetros e o poço PE na Chácara Esmeralda, com 169 h de bombeamento: a) indica a menor correlação $\mathrm{x} / \mathrm{y}$, de 1,55 ; e c) a maior, de 1,92 .

A Figura 8 demonstra que a menor diferença entre os eixos de máximo e mínimo $\mathrm{K}$ ocorre quando a elipse tem o eixo $x$ alinhado com o piezômetro PPE-2G. Por essa razão, foi o primeiro ângulo de orientação usado para aplicar a correção dos dados do teste de bombeamento. Na Chácara Esmeralda, a diferença encontrada é próxima àquela considerada aceitável por Hantush (1966): 1/2. Por isso, os ângulos utilizados para aplicar o método de Hantush (1966) são aqueles apresentados na Figura 9.

Para a interpretação dos dados são consideradas as seguintes direções de $\mathrm{T}$ :

$T_{\mathrm{X}}=\mathrm{T}$ em direção paralela à superfície de deposição das paleodunas, que é a de maior $\mathrm{K}$;

$T_{\mathrm{y}}=\mathrm{T}$ em direção perpendicular à superfície de deposição das paleodunas, que é a de menor $\mathrm{K}$;

$T_{1}=$ T na direção do piezômetro PPE-2G, com ângulo $\theta \mathrm{em}$ relação ao eixo $\mathrm{X}$ (valor apresentado na Tabela 2);

$T_{2}=$ T na direção do piezômetro PPE- $1 \mathrm{G}$, com ângulo $\theta+\alpha$ em relação ao eixo $X$ (valor apresentado na Tabela 2).

$\mathrm{AT}_{\mathrm{e}}$ obtida é de $1,49 \times 10^{-3} \mathrm{~m}^{2} / \mathrm{s}$. Aplicando a Equação 15 com os valores de $\mathrm{T}$ obtidos pelo método para aquíferos isotrópicos, obtém-se o valor de $\alpha_{2}$. Substituindo esse valor e os valores dos ângulos $\theta$ e $\alpha_{2}$ na Equação 13, obtém-se $m=1,55$.

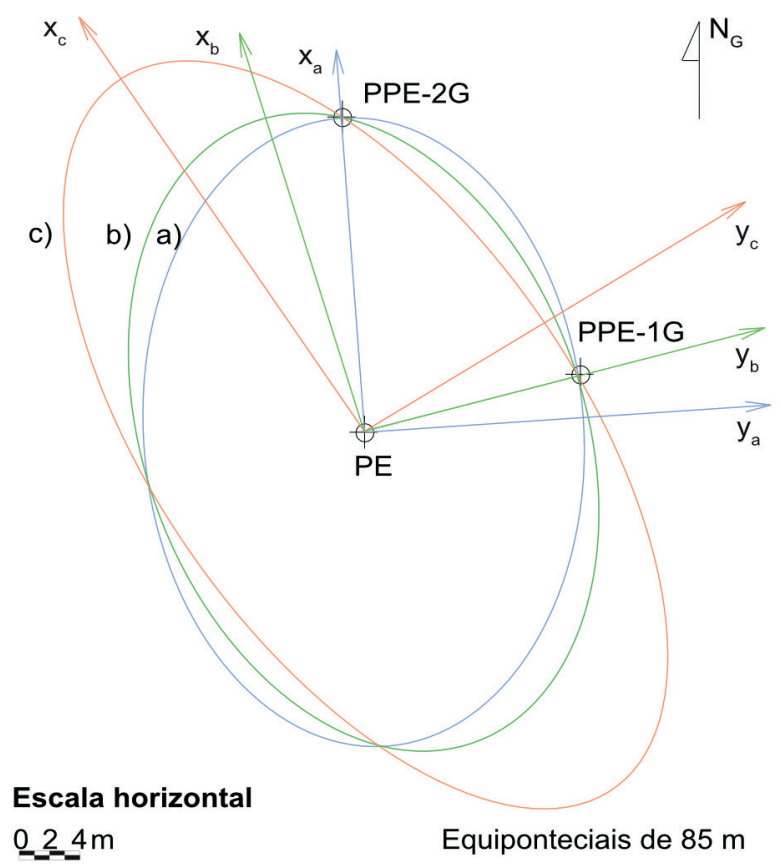

Figura 8. Exemplo de três orientações ( $a, b$ e c) de eixos $x$ (maior) e y (menor) da elipse formada pela equipotencial de 85 metros abaixo da superfície, baseadas em dados de rebaixamento medidos nos piezômetros profundos com filtros no Sistema Aquífero Guarani PPE-1G e PPE-2G após $169 \mathrm{~h}$ de bombeamento no Poço Esmeralda. Orientação a) indica a menor correlação x/y, de 1,55; e c), a maior, de 1,92. 
Conhecendo $m$, obtém-se $\mathrm{T}_{\mathrm{y}}$ e $\mathrm{T}_{\mathrm{x}}$ usando a Equação 14 . Como na situação proposta o eixo $x$ da elipse de $\mathrm{K}$ (e consequentemente de $\mathrm{T}$ ) está alinhado à direção do piezômetro PPE- $2 \mathrm{G}$, conclui-se que $\mathrm{T}_{\mathrm{x}}=\mathrm{T}_{1}$, e $\mathrm{T}_{2}$ pode ser recalculado: $\mathrm{T}_{1}=1,85 \times 10^{-3} \mathrm{~m}^{2} / \mathrm{s} \mathrm{e} \mathrm{T}=1,20 \times 10^{-3} \mathrm{~m}^{2} / \mathrm{s}$ (Tabela 2 ).

O valor de $m$ é a relação entre os extremos de T do aquífero. Caso tivesse sido usado um valor de $\theta$ diferente de $0^{\circ}$, o $m$ obtido teria sido ainda maior, como demonstrado na

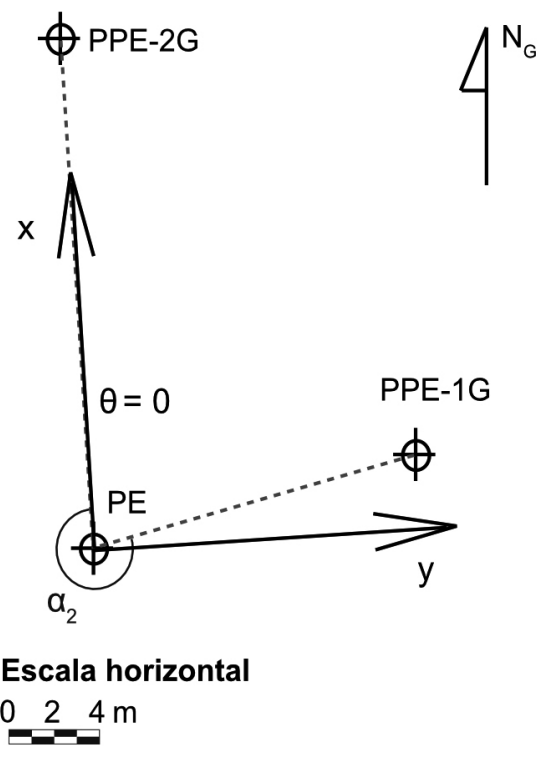

PPE-1G e PPE-2G: poços com piezômetros profundos com filtros no Sistema Aquífero Guarani; NG: norte geográfico; PE: Poço Esmeralda; $\theta$ : ângulo entre o eixo x e o piezômetro $1 ; \alpha_{2}$ : ângulo entre o piezômetro 1 e o piezômetro 2 .

Figura 9. Ângulos $\theta$ e $\alpha_{2}$ adotados para aplicar o método de Hantush (1966) para interpretação de teste de bombeamento em aquífero confinado com anisotropia. $\mathrm{O}$ alinhamento do piezômetro PPE-2G com o eixo $\mathrm{x}$ da elipse (ver Figura 8) faz com que o ângulo $\theta$ seja igual a zero.

Tabela 3. Relações de anisotropia entre os valores de transmissividade.

\begin{tabular}{lccc}
\hline & $P P E-1 G$ & $Y\left(T_{\text {min }}\right.$ e $\left.K_{\text {min }}\right)$ & $\begin{array}{c}P P E-2 G=x \\
\left(T_{\text {máx }} \text { e } K_{\text {máx }}\right)\end{array}$ \\
\hline$P P E-1 G$ & 1 & 1,02 & 0,66 \\
$y\left(T_{\text {min }} \in K_{\text {min }}\right)$ & 0,98 & 1 & 0,65 \\
$P P E-2 G=x$ & 1,52 & 1,55 & 1 \\
$\left(T_{\text {máx }} \in K_{\text {máx }}\right)$ & & & \\
\hline
\end{tabular}

PPE-1G: piezômetro profundo 1, com filtro no Sistema Aquífero Guarani; PPE-2G: piezômetro profundo 2, com filtro no Sistema Aquífero Guarani; y $\left(T_{\min }\right.$ e $\left.K_{\text {min }}\right)$ : direção $y$, na qual tanto a transmissividade quanto a condutividade hidráulica são mínimas; $x\left(T_{\text {max }}\right.$ e $K_{\text {max }}$ ): direção $x$, na qual tanto a transmissividade quanto a condutividade hidráulica são máximas.
Figura 8. O valor de 1,55 (Tabela 3) já é um pouco superior aos valores obtidos nos trabalhos de Lindquist (1988) e Van den Berg e Vries (2003), respectivamente de 1,45 e 1,46; indicando que a orientação escolhida para a elipsoide de anisotropia, com o eixo $x$ alinhado ao PPE-2G, é a mais provável. Assim, a orientação do elipsoide adotado é N-S para o eixo X, e E-W para o eixo Y.

A diferença entre o valor de $m$ apresentado aqui com relação aos autores mencionados pode ser causada por diversos fatores. Uma possibilidade é a influência de sedimentos interdunas, mais finos, e com $\mathrm{K}$ mais baixo. A geometria das superfícies de deposição também pode ser a origem da diferença. A penetração parcial do PE gera verticalização do fluxo. Quanto mais próxima a direção do fluxo for da orientação do eixo ortogonal aos planos de estratificações das paleodunas, maior será a anisotropia $\left(\mathrm{K}_{\min }\right.$ da Figura 2$)$. O trabalho de Lindquist (1988) somente avaliou a anisotropia entre as direções horizontal e vertical, e não em relação à direção ortogonal aos planos de estratificação. $\mathrm{O}$ trabalho de Van den Berg e Vries (2003) aborda essa questão, mas somente em sedimentos inconsolidados. Isso indica que a compactação dos sedimentos da Formação Botucatu pode ser outra causa do maior valor de $m$ obtido no presente trabalho.

\section{CONCLUSÕES}

A ausência de estabilização do nível dinâmico de água durante o teste de bombeamento de longa duração no SAG indica que a drenança de água, tanto por meio dos basaltos da Formação Serra Geral que recobrem o aquífero quanto dos sedimentos pelíticos da Formação Corumbataí, sotoposta a ele, é muito reduzida ou inexistente na área de influência do cone de rebaixamento. Os níveis de água nos piezômetros construídos no ASG levaram 14 dias após sua construção para estabilizar, indicando um baixo $\mathrm{K}$ desse aquitarde, sobretudo em maiores profundidades. As diferenças de níveis estáticos entre o ASG e SAG é de 12 m no PPE-1 e 77 m no PPE-2.

Os dados do teste de bombeamento também indicaram a presença de anisotropia no SAG. Fazendo as correções necessárias para a penetração parcial do poço de bombeamento e para a presença de anisotropia, foi calculado um $\mathrm{K}_{\text {máx }}$ de $8,1 \times 10^{-6} \mathrm{~m} / \mathrm{s}$, na direção $\mathrm{NNW}$, e um $\mathrm{K}_{\text {min }}$ de $5,2 \times 10^{-6} \mathrm{~m} / \mathrm{s}$, na direção ENE. Avalia-se que, com um piezômetro adicional na área, seria possível determinar com maior precisão a orientação do elipsoide de $\mathrm{K} \mathrm{e}$, por conseguinte, os valores de $\mathrm{K}_{\text {máx }}$ e $\mathrm{K}_{\text {mín }}$.

A relação entre a maior e a menor transmissividade $\left(\mathrm{T}_{\mathrm{x}} / \mathrm{T}_{\mathrm{y}}\right)$ no campo de piezômetros da Chácara Esmeralda foi de 1,55 , um pouco superior à encontrada por outros autores em sedimentos eólicos, como Van den Berg e Vries (2003), que obtiveram relação de 1,45; e Lindquist (1988), com valor de 1,46. 
Por outro lado, neste teste de bombeamento os piezômetros estavam praticamente no mesmo plano horizontal, que não é a direção de maior anisotropia em sedimentos eólicos com estratificações cruzadas. Nesse tipo de sedimento, a maior anisotropia ocorre entre a direção paralela às estratificações e sua perpendicular. Assim, é provável que a anisotropia entre as direções de $\mathrm{K}$ máximo e mínimo do SAG seja ainda maior do que 1,55, obtido neste trabalho.

Com base na orientação da anisotropia definida para a Chácara Esmeralda, é possível inferir a direção das camadas descritas pelas estratificações no arenito Botucatu como sendo ao redor de N-S. Como não é possível determinar o mergulho dessas camadas com os resultados do teste de bombeamento, o sentido das paleocorrentes de vento pode ser tanto leste quanto oeste. Medidas realizadas por Bigarella e Salamuni (1961) na Formação Botucatu indicaram predomínio geral de ventos em sentido sul no estado de São Paulo, com uma parte das medidas no entorno de São Carlos, indicando que ocorreram ventos em sentido oeste, portanto, de acordo com o que foi encontrado neste trabalho. Um teste de bombeamento com três pontos de monitoramento em direções distintas em relação ao poço bombeado, e com filtros dispostos em profundidades distintas, permitiria determinar com maior precisão a direção das estratificações, e consequentemente o sentido das paleocorrentes de vento no local.

\section{AGRADECIMENTOS}

Os autores agradecem a valiosa cooperação do Sr. Mário Osene, o apoio incondicional ao projeto "A Formação Serra Geral como conexão hidráulica entre o Sistema Aquífero Guarani e a superfície: análise estrutural e ensaios in situ" (FRATASG), permitindo a realização dos trabalhos na Chácara Esmeralda. Este trabalho foi financiado pela Fundação de Amparo à Pesquisa do Estado de São Paulo (FAPESP), na forma de um projeto de auxílio à pesquisa (processo 04/11798-4), e de uma bolsa de doutorado para o primeiro autor (processo 04/15543-0), que foi também apoiado pela Coordenação de Aperfeiçoamento de Pessoal de Nível Superior (CAPES), na forma de uma bolsa de doutorado sanduíche no exterior (processo 0715/06-9), e na forma de uma bolsa de doutorado (Demanda Social, Instituto de Geociências da Universidade de São Paulo - IGc/USP). A coordenação do projeto esteve a cargo do Instituto Geológico - SMA/ $\mathrm{SP}$ e o apoio de infraestrutura, a cargo do Laboratório de Modelos Físicos (LAMO) - IGc/USP e do Instituto Geológico - Secretaria do Meio Ambiente do Estado de São Paulo. Agradecimentos são estendidos a todos os integrantes e apoiadores do projeto FRATASG.

\section{REFERÊNCIAS}

Ahuja, L. R., Naney, J. W., Green, R. E., Nielsen, D. R. (1984). Macroporosity to characterize spatial variability of hydraulic conductivity and effects of land management. Soil Science Society of America Journal, 48, 699-702. https://doi. org/10.2136/sssaj1984.03615995004800040001x

Anderson, M. P. (1989). Hydrogeologic facies models to delineate large-scale spatial trends in glacial and glaciofluvial sediments. Geological Society of America Bulletin, 101, 501-511. https://doi.org/10.1130/0016-7606(1989)101<0501:HFMT DL $>2.3 . C O ; 2$

Araújo, L. M., França, A. B., Potter, P. E. (1999). Hydrogeology of the Mercosul Aquifer System in the Chaco-Paraná Basins, South America. and Comparison with the Navajo-Nugget Aquifer System, USA. Hydrogeology Journal, 7(3), 317-336. https://doi.org/10.1007/s100400050205

Assine, M. L., Piranha, J. M., Carneiro, C. D. R. (2004). Os Paleodesertos Pirambóia e Botucatu. In: V. Mantesso Neto, A. Bartorelli, B. B. Brito-Neves, C. D. R. Carneiro (eds.). Geologia do Continente Sul-Americano: Evolução da Obra de Fernando Flávio Marques de Almeida, p. 77-93. São Paulo: Beca, p. 77-93.

Bear, J. (1979). Hydraulics of groundwater. McGraw-Hill series in water resources and environmental engineering. Nova York: McGraw-Hill. 567 p.

Bigarella, J. J., Salamuni, R. (1961). Early Mesozoic Wind Patterns as Suggested by Dune Bedding in the Botucatú Sandstone of Brazil and Uruguay. Geological Society of America Bulletin, 72(7), 1089-1105. https://doi. org/10.1130/0016-7606(1961)72[1089:EMWPAS]2.0.CO;2

Bjerg, P. L., Hinsby, K., Christensen, T. H., Gravesen, P. (1992). Spatial variability of hydraulic conductivity of an unconfined sandy aquifer determined by a mini slug test. Journal of Hydrololgy, 136, 107-122. https://doi. org/10.1016/0022-1694(92)90007-I

Burger, R. L., Belitz, K. (1997). Measurement of anisotropic hydraulic conductivity in unconsolidated sands: A case study from a shoreface deposit, Oyster, Virginia. Water Resources Research, 33(6), 1515-1522. https://doi. org/10.1029/97WR00570

Blöcher, G. (2004). Grundwasserbewirtschaftung mittels eines dreidimensionalen numerischen Strömungsmodels im Raum Ribeirão Preto - São Paulo - Brasilien. Dissertação (Mestrado). Berlim: Universidade Técnica de Berlim. 
Caetano-Chang, M. R. (1997). A Formação Pirambóia no centro-leste do estado de São Paulo. Tese (Livre Docência em Geologia). Rio Claro: Instituto de Geociências e Ciências Exatas - UNESP.

Caetano-Chang, M. R., Wu, F. T. (1992). Bacia do Paraná: formações Pirambóia e Botucatu. XXXVII Congresso Brasileiro de Geologia. Roteiro de Excursão São Paulo, v. 2, 1-19. São Paulo: SBG.

Departamento de Águas e Energia Elétrica (DAEE). (1974). Estudo de Águas Subterrâneas - Região Administrativa 6 Ribeirão Preto. São Paulo: DAEE. 2 v.

Fernandes, A. J., Maldaner, C., Azevedo Sobrinho, J. M., Pressinotti, M., Wahnfried, I. (2010). Estratigrafia dos derrames de basaltos de Ribeirão Preto: geologia física, petrografia e geoquímica. Geologia USP. Série Científica, 10(2), 73-99. http://dx.doi.org/10.5327/Z1519-874X2010000200006

Fernandes, A. J., Maldaner, C., Negri, F., Rouleau, A., Wahnfried, I. (2016). Aspects of a conceptual groundwater flow model of the Serra Geral basalt aquifer (São Paulo, Brazil) from physical and structural geology data. Hydrogeology Journal, 24, 1199-1212. https://doi. org/10.1007/s10040-016-1370-6

Fernandes, A. J., Maldaner, C., Rouleau, A. (2011). Análise de fraturas nos basaltos de Formação Serra Geral (Ribeirão Preto, SP): aplicação para a elaboração de modelo hidrogeológico conceitual. Geologia USP. Série Científica, 11(3), 43-64. http://dx.doi.org/10.5327/Z1519-874X2011000300003

Foster, S., Hirata, R., Vidal, A., Schmidt, G., Garduño, H. (2009). The Guarani Aquifer Initiative - Towards Realistic Groundwater Management in a Transboundary Context. Washington, D.C.: World Bank-Groundwater Management Advisory Team. Case Profile Collection, 9, 16 p.

Freeze, R. A., Cherry, J. A. (1979). Groundwater. Englewood Cliffs: Prentice-Hall. 604 p.

Gallo, G., Sinelli, O. (1980). Estudo hidroquímico e isotópico das águas subterrâneas na região de Ribeirão Preto. Revista Brasileira de Geociencias, 10, 129-140.

Hantush, M. S. (1961a). Aquifer Tests on a Partially Penetrating Wells. Proceedings of the American Society of Civil Engineers, 87 (HY5), 171-195. J. Hydraulic Division.

Hantush, M. S. (1961b). Drawdown Around a Partially Penetrating Well. Proceedings of the American Society of Civil Engineers, 87 (HY4), 83-98. J. Hydraulic Division.
Hantush, M. S. (1966). Analysis of data from pumping tests in anisotropic aquifers. Journal Geophysical Research, 71(2), 421-426. https://doi.org/10.1029/JZ071i002p00421

Hirata, R., Conicelli, B., Pinhatti, A., Luiz, M. B., Porto, R., Ferrari, L. C. K. M. (2015). O Sistema Aquífero Guarani e a crise hídrica nas regiões de Campinas e São Paulo. Revista USP, 106, 59-70. http://dx.doi.org/10.11606/issn.2316-9036.v0i106p59-70

Hirata, R., Gesicki, A., Sracek, O., Bertolo, R., Gianinni, P., Aravena, R. (2011). Relation between sedimentary framework and hydrogeology in the Guarani Aquifer System in São Paulo state, Brazil. Journal of South American Earth Sciences, 31, 444-456. https://doi.org/10.1016/j.jsames.2011.03.006

Instituto Brasileiro de Geografia e Estatística (IBGE). (2016). Cidades - Estimativas da população de Ribeirão Preto/SP para 2015. Disponível em: <http://cod.ibge.gov.br/7JY>. Acesso em: 3 ago. 2016.

Instituto de Pesquisas Tecnológicas do Estado de São Paulo (IPT), Coordenadoria de Planejamento Ambiental (CPLA) (2011). Subsídios o Plano de Desenvolvimento e Proteção Ambiental da Área de Afloramento do Sistema Aquífero Guarani no Estado de São Paulo. Cadernos do Projeto Ambiental Estraégico Aquiferos. São Paulo: Publicações IPT. 103 p.

Iritani, M. A. (ed.). (2004). Sistema de Informação para o Gerenciamento Ambiental dos Recursos Hídricos Subterrâneos na Área de Afloramento do Aquífero Guarani no Estado de São Paulo, Relatório Final de Projeto de Pesquisa FAPESP, n. 02/10368-0. São Paulo. 148 p.

Iritani, M. A., Schuler, G., Dias, C. L., Ferreira, L. M. R., Guaillaumon, J. R., Frish, H., Casarini, D. C. P., Tröger, U. (2004). Exploração do Aqüífero Guarani e os impactos ao nível d'água em Ribeirão Preto Brasil. $33^{\text {rd }}$ Congress International Association of Hydrogeologists. Anais. Zacatecas, México.

Kruseman, G. P., de Ridder, N.A.(1991). Analysis and Evaluation of Pumping Test Data. $2^{\mathrm{a}}$ ed. Wageningen: International Institute for Land Reclamation and Improvement. 377 p.

Lindquist, S. J. (1988). Practical Characterization of Eolian Reservoirs for Development: Nugget Sandstone, Utah-Wyoming Thrust Belt. Sedimentary Geology, 56, 315-339. https://doi.org/10.1016/0037-0738(88)90059-0

Massoli, M. (2007). Caracterização Litofaciológica das Formações Pirambóia e Botucatu, em Subsuperfície, no Município de Ribeirão Preto (SP), e sua Aplicação na Prospecção de Águas Subterrâneas. Tese (Doutorado). Rio Claro: Instituto de Geociências e Ciências Exatas - UNESP. 
Milani, E. J., França, A. B., Schneider, R. L. (1994). Bacia do Paraná. Boletim Geociências da Petrobras, 8(1), 69-82.

Moore, P. J. (1979). Determination of Permeability Anisotropy in a Two-Way Permeameter. Geotechnical Testing Journal, 2(3), 167-169.

Organização dos Estados Americanos (OEA). (2009). Aquifero Guarani: programa estratégico de ação. Brasil, Argentina, Paraguai, Uruguai: OEA. 424 p.

Paula e Silva, F., Kiang, C. H., Caetano-Chang, M. R., Sinelli, O. (2008). Arcabouço geológico e hidrofácies do Sistema Aquífero Guarani, no município de Ribeirão Preto (SP). Revista Brasileira de Geociências, 38(1), 56-67.

Perrotta, M. M., Salvador, E. D., Lopes, R. C., D’Agostino, L. Z., Peruffo, N., Gomes, S. D., Sachs, L. L. B., Meira, V. T., Lacerda Filho, J. F. (2005). Mapa Geológico do Estado de São Paulo, escala 1:750.000. Programa Levantamentos Geológicos Básicos do Brasil. São Paulo: CPRM.

Silva, R. B. G. (1983). Estudo hidroquímico e isotópico das águas subterrâneas do Aqüifero Botucatu no Estado de São Paulo. Tese (Doutorado). São Paulo: Instituto de Geociências USP. https://doi.org/10.11606/T.44.1983.tde-28082015-135247

Sinelli, O. (ed.). (1973). Mapa geológico do nordeste do Estado de São Paulo. Escala 1:50.000 - Folhas de Serrana,
Ribeirão Preto, Cravinhos e Bonfim Paulista. Ribeirão Preto: Convênio CNEC/FFCL - USP/Ribeirão Preto.

Sracek, O., Hirata, R. (2002). Geochemical and stable isotopes evolution of the Guarani Aquifer System in the State of São Paulo, Brazil. Hydrogeology Journal, 10(6), 643-655. https://doi.org/10.1007/s10040-002-0222-8

Takahashi, A. (2005). Aquífero Guarani. In: Governo do Estado de São Paulo (ed.). Mapa de águas subterrâneas do Estado de São Paulo em 1:1.000.000. São Paulo: DAEE/ IG-SMA/IPT/CPRM. Nota explicativa.

Theis, C. V. (1935). The relation between the lowering of the piezometric surface and the rate and duration of discharge of a well using groundwater storage. Transactions of the American Geophysical Union, 16, 519-524. https://doi. org/10.1029/TR016i002p00519

Van den Berg, E. H., Vries, J. J. (2003). Influence of grain fabric and lamination on the anisotropy of hydraulic conductivity in unconsolidated dune sands. Journal of Hydrology, 283, 244-266. https://doi.org/10.1016/S0022-1694(03)00272-5

Wahnfried, I. (2010). Modelo conceitual de fluxo do Aquitarde Serra Geral e do Sistema Aquifero Guarani na região de Ribeirao Preto, SP. Tese (Doutorado). São Paulo: Instituto de Geociências - USP. https://doi.org/10.11606/T.44.2010. tde-07072010-163245 